
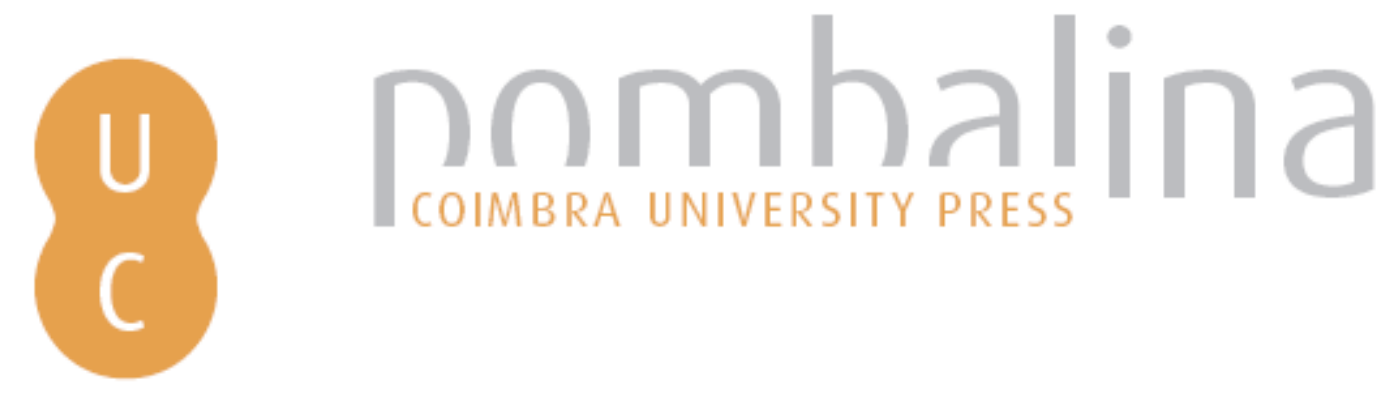

\title{
Os planos regionais de ordenamento do território e a coesão territorial: reflexões sobre a sub-região oeste
}

\author{
Autor(es): $\quad$ Gil, Daniel Nascimento Matoso \\ Publicado por: Imprensa da Universidade de Coimbra \\ URL \\ persistente: URI:http://hdl.handle.net/10316.2/30811 \\ DOI: $\quad$ DOI:http://dx.doi.org/10.14195/978-989-26-0244-8_37 \\ Accessed : $\quad$ 26-Apr-2023 12:58:54
}

A navegação consulta e descarregamento dos títulos inseridos nas Bibliotecas Digitais UC Digitalis, UC Pombalina e UC Impactum, pressupõem a aceitação plena e sem reservas dos Termos e Condições de Uso destas Bibliotecas Digitais, disponíveis em https://digitalis.uc.pt/pt-pt/termos.

Conforme exposto nos referidos Termos e Condições de Uso, o descarregamento de títulos de acesso restrito requer uma licença válida de autorização devendo o utilizador aceder ao(s) documento(s) a partir de um endereço de IP da instituição detentora da supramencionada licença.

Ao utilizador é apenas permitido o descarregamento para uso pessoal, pelo que o emprego do(s) título(s) descarregado(s) para outro fim, designadamente comercial, carece de autorização do respetivo autor ou editor da obra.

Na medida em que todas as obras da UC Digitalis se encontram protegidas pelo Código do Direito de Autor e Direitos Conexos e demais legislação aplicável, toda a cópia, parcial ou total, deste documento, nos casos em que é legalmente admitida, deverá conter ou fazer-se acompanhar por este aviso.

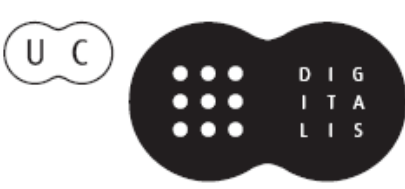




\section{TRUNFOS DE UMA}

\section{EOGRAFIA ACIVA}

\section{DESENVOLVIMENTO LOCAL,}

AMBIENTE,

ORDENAMENTO

E TECNOLOGIA

Norberto Santos

Lúcio Cunha

COORDENAÇÃO 
Daniel Nascimento Matoso Gil

e-Geo - Centro de Estudos de Geografía e Planeamento Regional

Faculdade de Ciências Sociais e Humanas, Universidade Nova de Lisboa

\section{OS PLANOS REGIONAIS DE ORDENAMENTO DO TERRITÓRIO E A COESĀO TERRITORIAL: REFLEXÓES SOBRE A SUB-REGIÃO OESTE ${ }^{1}$}

\section{O NOVO ENQUADRAMENTO DE UMA «VELHA» QUESTÃO}

O conceito de Coesão Territorial tem raízes espalhadas por vários campos de estudo e a discussão das suas características começa a ganhar importância nos anos 90 (com a elaboração de documentos como o «Europa 2000» e o EDEC). Pode-se mesmo dizer que as ideias subjacentes ao conceito de Coesão Territorial não constituem uma novidade no vocabulário do ordenamento do território. A inovação reside no novo enquadramento dado ao conceito que, com a aprovação do Tratado de Lisboa, se tornou no terceiro pilar da política de coesão europeia, a par da coesão económica e da coesão social. Neste enquadramento, o conceito surge como reacção a dois aspectos: a interiorização, por parte de várias instituiçóes europeias, dos desequilíbrios territoriais provocados pela aplicação das políticas sectoriais e o desejo de desconcentrar o espaço europeu, caracterizado por ter apenas uma única área de inclusão económica mundial, o chamado "pentágono europeu». A Coesão Territorial posiciona-se como uma forma para contrabalançar este modelo, ao questionar se a União Europeia está a aproveitar todo o seu potencial.

$\mathrm{Na}$ sua base, o conceito adopta dois princípios. O primeiro é o conceito de capital territorial que representa os recursos endógenos de um dado território. Cabe às políticas públicas, acima de tudo, desenvolver o capital territorial de uma regiáo (único em cada uma delas), maximizando as suas vantagens competitivas. $\mathrm{O}$ segundo princípio passa pela internalização dos impactos das políticas sectoriais e a necessidade de proceder à sua articulação e procurar novas formas de governação. Estes princípios subjacentes estão também reflectidos no «Livro Verde sobre a Coesão Territorial Europeia: Tirar Partido da Diversidade Territorial», lançado pela Comissão Europeia a 6 de Outubro de 2008. O Livro Verde apresenta o tema da Coesão Territorial da seguinte maneira:

«Da tundra gelada do círculo polar Árctico à floresta tropical da Guiana, dos Alpes às ilhas gregas, das cosmopolitas Londres e Paris às pequenas cidades e vilas seculares, a UE abriga uma diversidade territorial extraordinariamente rica. A coesão territorial procura alcançar o

\footnotetext{
${ }^{1}$ Elaborado no âmbito do projecto "Territorial Cohesion in Portugal: new insights for spatial planning", apoiado pelo Programa Plurianual de Financiamento da Fundação para a Ciência e a Tecnologia.
} 
desenvolvimento harmonioso de todos estes territórios e facultar aos seus habitantes a possibilidade de tirar o melhor partido das caracteristicas de cada um deles. Nessa medida, a coesão territorial é um factor de conversão da diferença em vantagem, contribuindo, assim, para o desenvolvimento sustentável de toda a EU». (CEC 2008, p.3)

A introduçáo do tema é vaga, e esta característica persiste em todo o documento, o que não é de entranhar, e possivelmente até recomendável, atendendo ao seu carácter exploratório.

Como conceito, a coesão territorial não é completamente clara nas suas intençóes, algo que o próprio Livro Verde reconhece: «a procura da Coesão Territorial beneficiaria de uma clarificação das múltiplas temáticas que suscita» (CEC 2008, p.4). Apesar desta limitação, o Livro Verde propóe três frentes de acção, apelidadas de "os três C» (Concentration, Connection e Cooperation) para construir uma UE mais coesa:

Concentração: Ultrapassar as diferenças de densidade - esta frente de acção aborda o policentrismo, que se pode considerar como o modelo territorial da coesáo territorial. A construção de um sistema urbano policêntrico é de extrema relevância para o conceito por duas razóes: promove um modelo económico mais competitivo, assente em complementaridades e especializaçóes que só a inserção em rede permite e leva a uma distribuição mais equitativa de equipamentos públicos e de serviços de interesse geral, garantindo uma maior igualdade no acesso por parte da população.

Conexão (Interligar Territórios): eliminar as distâncias - a intermodalidade dos transportes e o acesso aos serviços de saúde, educação e tecnologias de informaçáo e comunicação são valorizadas, apelando também a uma maior ligação entre as estruturas empresariais e as unidades de investigação científica.

Cooperação: eliminar divisóes - esta frente de acção assume-se como transversal em relação às outras duas, uma vez que é referido que a soluçáo para os problemas de concentraçáo e interligação só é possível através de uma forte cooperação a todos os níveis e escalas.

Estas frentes de acção constituem algumas pistas para um processo de debate futuro que espera alcançar uma operacionalização do conceito, sob a forma de um eventual "Livro Branco sobre a Coesão Territorial Europeia».

\section{COESÃO TERRITORIAL EM PORTUGAL: QUE INDÍCIOS?}

Apesar destas incertezas a nível europeu, a verdade é que o conceito de Coesão Territorial, nos moldes em que é defendido actualmente, já marca presença no sistema português de ordenamento do território. Ao analisar documentos de âmbito nacional, como o QREN, ENDS, PNPOT e POLIS XXI, é possível encontrar linhas de orientação que em muito reflectem os «3 $\mathrm{c}$ » do Livro Verde. O enfoque dado a temas centrais ao conceito de Coesáo Territorial como a consolidaçáo do sistema urbano e das redes de equipamentos, o policentrismo, o fomento do capital territorial, um melhor acesso a serviços de interesse geral, a cooperação territorial, as preocupaçóes ambientais e ainda a procura de novos modelos de governança (entre outros), revela que já existe um enquadramento da Coesão Territorial no sistema de ordenamento português. Articulados, estes documentos formam uma complexa rede de orientaçóes a diferentes escalas, assegurando, num plano teórico, as condiçôes necessárias à condução de uma política onde a construção de um território mais coeso ocupa um lugar central. 
É neste contexto que surge a nova geração de PROT. Reconhecendo as limitaçóes e erros da primeira geração (que privilegiou a componente normativa em detrimento da programática), a segunda geração é caracterizada pela sua natureza estratégica e articulação de políticas. Esta componente estratégica da dimensão regional é essencial, pois esta escala está assim capacitada para desempenhar um papel fundamental de charneira (entre o nível nacional e o municipal) no sistema de ordenamento, sendo possível a coordenação das políticas sectoriais, a definição de um modelo de ocupação, uma visão estratégica e as orientaçóes para a alcançar. Será esta nova geração de planeamento regional adequada para orientar o processo de construçáo de um território mais coeso? Para responder a esta pergunta será estudado o caso do PROT OVT.

\section{PROT OVT: CONTRIBUTOS PARA UM TERRITÓRIO MAIS COESO}

O PROT OVT, publicado em Agosto de 2009, entrou em vigor no dia 1 de Novembro de 2009, tornando-se o terceiro PROT em vigor no território de Portugal Continental (a seguir ao PROTAML e ao PROTAL). O Oeste e Vale do Tejo insere-se no espaço de polarização da AML. O seu esquema de desenvolvimento reflecte as dinâmicas da Região de Lisboa, mas para fins de programaçáo comunitária, o OVT é enquadrado pelas opçóes das regióes do Centro e Alentejo. Situada entre estas três regióes, existe um potencial para que este território venha a desempenhar um importante papel de charneira.

Em traços gerais, a sub-região do Oeste é caracterizada por um sistema urbano «fortemente polarizado pela Área Metropolitana de Lisboa, que tende a integrar a dinâmica das cidades médias mais próximas» (DGOTDU, 2002:290). O desenvolvimento da rede de transportes, em particular o rodoviário (devido à conclusão da $\mathrm{A} 8$ ), tem favorecido a consolidação do sistema urbano através de uma difusão, seguindo um padrão policêntrico, de equipamentos, comércio, serviços, industrialização e urbanização que se assume cada vez mais como uma extensão da coroa periférica da AML. Economicamente, a sub-regiáo do Oeste é conhecida pela forte presença do sector agrícola na sua economia, sobretudo nas áreas da horticultura e fruticultura, constituindo um dos aspectos mais marcantes do território.

O Oeste é então um território dinâmico. Mas qual é a sua identidade? O que distingue esta sub-região do território envolvente? Para responder a esta questão foi indispensável ouvir os protagonistas locais ${ }^{2}$, com base em entrevistas estruturadas. As opiniôes expressas são diversas, mas, no geral, reconhece-se que se trata de um território em transformação e com várias identidades. A CM Alcobaça fala de uma região incaracterística e muito diversa mas que nem sempre foi assim: «o Oeste há muitos anos era mais singular e tinha uma identidade mais forte do que agora. A boa agricultura e as pescas perderam-se e o que restou foram algumas marcas, sob a forma de produtos tradicionais e monumentos históricos, desaparecendo a unidade, identidade e tradiçóes». A representante da equipa técnica do PROT partilha esta dificuldade em encontrar elementos identificadores. Afirma que «o Oeste é uma NUT III, mas não sei se tem uma identidade como região». Ainda assim identifica alguns elementos que caracterizam o Oeste como a paisagem (salientando a qualidade do litoral) e o

\footnotetext{
${ }^{2}$ Câmaras Municipais de Torres Vedras, Caldas da Rainha e Alcobaça, responsáveis da equipa técnica do PROT OVT e CCDRLVT, Associação de Desenvolvimento Regional do Oeste e Turismo Oeste.
} 
ideal de «Quintal de Lisboa» (uma área de descanso e um rural idílico para os «urbanitas»), o que explica a criação de uma imagem para a sub-região em torno do conceito de "Coroa Verde da Área Metropolitana Central. A ADRO reconhece que este conceito tem razão de ser. Explica que a sub-regiáo nunca foi muito industrializada, apenas em alguns focos (Alenquer, Caldas da Rainha e Alcobaça). Sempre viveu à base da agricultura, constituindo este sector um dos identificadores mais forte do Oeste. A representante da CCDR vai de encontro a estas afirmaçóes, ao referir que o Oeste é, de certa forma, um contraponto à cidade de Lisboa, uma sua variante. Beneficia da proximidade à cidade (ganhando mercado e atraindo actividades com a ajuda das boas acessibilidades), mas sem os problemas de estar integrado directamente nesse território. Como elementos identificadores aponta a paisagem, o clima, o turismo/recreio/lazer e a agricultura. Segundo o município de Torres Vedras, a estrutura agrícola tem alguma pujança, sendo o concelho mais produtivo em Portugal no sector hortícola. Em relação às características do povoamento, a sua localização no litoral, tem evitado o despovoamento do espaço rural. Não há o esvaziamento das aldeias porque a cidade não tem um peso excessivo. A relaçáo com a AML é também apontada pela $\mathrm{CM}$ Caldas da Rainha. Na sua opiniáo, o Oeste assume-se como um complemento e como um espaço natural de descompressão de uma região muito concentrada. Apontam também três vectores de identificação do território: paisagem, cultura e serviços, polarizados em diversas cidades de pequena e média dimensão. Já o Turismo do Oeste, ao referir a relação com a cidade de Lisboa, afirma que «esta situação de charneira não é uma invenção do PROT, é algo que sempre existiu. Convivemos perfeitamente com isso, sem problemas muito significativos e o PROT, em definitivo, penso, cria condiçóes para manter este conceito de «ruralidade moderna»».

Feito este enquadramento inicial do território do Oeste, de que maneira é que o PROT OVT contribui para a construção de um território mais coeso? A visão delineada pretende transformar o OVT, no horizonte de 2020, num dos territórios mais qualificados, atractivos e produtivos do país, através da concretização de quatro eixos estratégicos: ganhar a aposta da inovação, competitividade e internacionalização (eixo 1), potenciar as vocaçóes territoriais num quadro de sustentabilidade ambiental (eixo 2), concretizar a visão policêntrica e valorizar a qualidade de vida urbana (eixo 3) e descobrir as novas ruralidades (eixo 4).

Tendo em conta o enquadramento anterior das questốes relacionadas com a Coesão Territorial torna-se claro que estes estão presentes no PROT OVT. Os eixos 1 e 2 reflectem o ênfase da necessidade do processo de desenvolvimento assentar no capital territorial como forma de construir um modelo económico mais inovador e voltado para o exterior, o eixo 3 remete para o policentrismo e o 4 para a importância das relaçóes urbano-rural. Para alcançar estes eixos foram definidos três sistemas (económico/ /competitividade, ambiente e mobilidade) que estruturam o modelo territorial, do qual, sinteticamente, se retiram as seguintes orientaçóes:

O sistema urbano do Oeste estrutura-se em torno do eixo Torres Vedras - Caldas da Rainha - Alcobaça, apoiado na A8, que constitui a principal ligação com a AML e com a cidade de Leiria. A posição hierárquica superior destas três cidades justifica a localização dos três parques de negócios regionais. Outras cidades que se destacam no sistema urbano do Oeste são Alenquer (devido à sua funçáo de porta norte da AML), Óbidos, Peniche e Nazaré (todas zonas turísticas de interesse). No litoral, multiplicam-se os núcleos de turismo e lazer (NTL), seguindo assim a estratégia delineada no PENT, o que em conjunto com a aposta 
turística nas cidades de Alcobaça, Óbidos (ambas integradas no arco do património), Nazaré e Peniche faz do turismo uma das principais vertentes estratégicas e alavancas de desenvolvimento propostas no PROT OVT. Seguindo a grande tradição agrícola do Oeste (especialmente nos sectores hortícola e frutícola), são delineadas três áreas de desenvolvimento agrícola e florestal: horticultura e floresta de produção (na faixa costeira), fruticultura e viticultura (mais no interior) e floresta de produção e olivicultura. No ambiente, estão delimitados dois corredores ecológicos estruturantes que atravessam toda a faixa costeira e ainda o território mais interior, correspondendo em parte às duas serras (também classificadas como áreas nucleares estruturantes). No que toca ao sistema de mobilidade, a principal aposta passa pelo transporte ferroviário, assegurado pela presença da linha do Oeste, que há muito perdeu o protagonismo que teve no desenvolvimento local. A sua reabilitação é prioritária, estando a ser estudada a sua eventual ligação com a linha do Norte e a construçáo de uma ligação ferroviária directa com Lisboa. A alta velocidade marca presença no território, pois está prevista uma estação em Rio Maior que servirá o Oeste.

O modelo territorial reflecte entáo uma aposta nos sectores do turismo, agricultura/floresta e centros de acolhimento empresarial enquadrados na dinâmica do sistema urbano, aproveitando as excelentes condiçóes de mobilidade da regiáo. Apresentadas as orientaçóes do PROT é possível afirmar que existe uma concordância entre este instrumento e o conceito de Coesão Territorial.

Tendo em conta as preocupaçóes territoriais que o conceito de Coesão Territorial manifesta, é natural que o objectivo seja um desenvolvimento territorial harmonioso. $\mathrm{O}$ PROT, como IGT, assume também este objectivo. Neste contexto, e tal como é defendido no Livro Verde sobre a Coesão Territorial, a palavra de ordem do PROT OVT é concentração. A dispersão é o principal problema de ordenamento presente no território, o que se deve à estrutura da propriedade e às boas acessibilidades da sub-regiáo, que propiciam formas de ocupação lineares em torno dos eixos de circulação. Neste domínio, o estabelecimento de 4 hectares como dimensão mínima da parcela para construção em espaço rural (ou 2 hectares consoante a estrutura fundiária do município) constitui uma medida vigorosa no combate à dispersão. Espera-se assim a construção de um território onde os diferentes usos convivam de forma harmoniosa, preservando a paisagem e as identidades, onde se definem novas lógicas de localização das actividades económicas, tornando-as mais competitivas, e onde a população possa usufruir com melhor acessibilidade dos serviços e equipamentos a funcionar no território.

No que toca à redução das disparidades socioeconómicas, o documento do PROT OVT referencia explicitamente a redução das disparidades de desenvolvimento no interior da sub-região (entre o litoral e o interior). Apesar desta intenção, não é claro o caminho adoptado para colmatar esta falha. Tendo em conta a forte aposta no turismo (maioritariamente concentrado na faixa litoral), é mesmo possível que as disparidades possam, até, acentuar-se.

$\mathrm{Na}$ área da competitividade económica, o capital territorial constitui a base onde assenta a proposta para o modelo de desenvolvimento económico da sub-região do Oeste. No geral, foi conseguida uma selectividade estratégica, apostando-se em sectores que não só têm um importante peso na economia regional, como também apresentam um maior potencial de crescimento e de internacionalização. Posto isto, o futuro da competitividade económica no Oeste passa pelo incremento da agricultura e do turismo (no seguimento das orientações do PENT, que classifica o Oeste como área de expansão prioritária), pois 
constituem os melhores pontos de inserção em lógicas de internacionalização e de complementaridade com outros territórios.

A existência de um eixo estratégico dedicado em exclusivo ao mundo rural denota a atenção dada às relaçóes urbano-rural. As orientaçóes do PROT OVT convergem com o defendido no conceito de Coesão Territorial: é preconizada a multifuncionalidade das exploraçôes agrícolas e a sua integração nos espaços urbanos, formando uma relação simbiótica entre ambos. As áreas rurais são essenciais para a manutenção da diversidade territorial e, neste âmbito, o PROT procura aproximar o rural do urbano sem, no entanto, o descaracterizar (com as suas vivências e apropriaçáo do espaço específicas).

A um nível conceptual, tanto o conceito de coesão territorial como a figura de plano do PROT enfatizam a necessidade de coordenar políticas, tendo como base um nível territorial. Representam também uma tentativa de acabar com o excessivo sectarismo das políticas sectoriais, alertando para os perigos desta abordagem. Descrito este enquadramento, os paralelos entre o conceito de Coesão Territorial e o PROT na área de coordenação são evidentes. Neste campo, o PROT OVT teve sucesso e conseguiu impor-se como uma plataforma de concertação entre as orientaçóes nacionais e as expectativas municipais. A integração das opçóes de desenvolvimento contidas em documentos como o PROT, a ENDS e o PENT está bem patente, o único contratempo a apontar prende-se com o QREN, uma vez que não se concretizaram as pretensóes iniciais do PROT constituir o referencial de elaboração dos POR (tendo estes surgido primeiro). A articulação com o nível municipal conheceu algumas dificuldades, nomeadamente em relaçáo às questôes da edificabilidade em espaço rural e na faixa litoral $(500 \mathrm{~m})$, acabando por se registarem alteraçóes no documento original aquando da sua publicação no Diário da República. No entanto, a participação intensa ao longo do processo de elaboração permitiu estabelecer o PROT como uma plataforma de concertação, o que levou à formulação de uma estratégia comum assimilada por todos. As hipóteses de execução do plano são, assim, muito maiores.

\section{CONCLUSŌES}

$\mathrm{O}$ actual enquadramento do conceito de Coesão Territorial, embora não seja uma novidade, constitui um estado mais avançado, uma actualizaçáo face aos novos desafios que os territórios enfrentam, ao mesmo tempo que mantém vivo o espírito do EDEC. Através da sua inserção como terceiro pilar da política de coesão europeia e do lançamento do Livro Verde sobre a Coesáo Territorial, o conceito tem sido amplamente discutido nos últimos anos e parece haver vontade de o operacionalizar. Embora ainda exista um caminho a percorrer para clarificar o conceito, já existe uma sólida base de trabalho, se bem que a um nível ainda muito informal. O desafio futuro passará, com certeza, pela formalização do conceito como política europeia.

A nível nacional, a Coesão Territorial está presente na legislação portuguesa, constituindo uma sólida base de trabalho para uma eventual operacionalizaçáo do conceito. Destaca-se o papel a desempenhar pelos PROT de segunda geração, que constituem a charneira entre o nível nacional e municipal. Estes instrumentos possuem as ferramentas necessárias para cumprir a função de coordenação de políticas, podendo dar um contributo decisivo na construção de um território mais coeso. 
O PROT OVT «cria» uma sub-região que nunca existiu, formada por três NUT III com fraca história de cooperação entre si. Apesar destas limitaçóes, foi possível encontrar uma estratégia comum onde todos se revêem. Na sub-regiáo do Oeste e Vale do Tejo, o Oeste constitui um caso curioso. Associada a várias identidades e fortemente polarizada pela AML, o Oeste é um território dinâmico à procura de uma identidade comum. $\mathrm{O}$ PROT OVT conseguiu delinear uma estratégia que não descura o potencial endógeno da sub-região (assente na agricultura e no turismo) e utiliza-o de forma a integrá-lo na rede urbana nacional, com especial ênfase para a da região de polarização metropolitana. É esta sua inserção que vai permitir algum grau de internacionalização. A valorização do capital territorial, junto com a protecção dos valores naturais e com o combate à dispersão urbana, permite também a protecção da identidade territorial do Oeste. O PROT OVT, através da coordenação de políticas, construção de uma visão estratégica futura assente no capital territorial, protecção da(s) identidade(s) regional e mediação de agentes (apoiando a construção de redes de cooperaçáo territorial), representa, assim, um passo inequívoco no caminho para a Coesão Territorial.

\section{REFERÊNCIAS BIBLIOGRÁFICAS}

CCDRLVT 2009, Plano Regional de Ordenamento do Território do Oeste e Vale do Tejo; de http://protovt.inescporto.pt/ /area-publica/PROT-OVT_\%20VERSaO\%20APROVADA.pdf;

CEC 2008, Livro Verde Sobre a Coesão Territorial Europeia: Tirar Partido da Diversidade Territorial, COM(2008) 616 final, Bruxelas; de http://ec.europa.eu/regional_policy/consultation/terco/paper_terco_pt.pd;

DGOTDU 2002, Sistema Urbano Nacional: Rede Complementar; DGOTDU, Lisboa;

DGOTDU 2007, Programa Nacional da Política de Ordenamento do Território; de http://www.territorioportugal.pt/ /pnpot/;

Faludi, Andreas 2009, Territorial Cohesion under the Looking Glass; de http://ec.europa.eu/regional_policy/ /consultation/terco/pdf/lookingglass.pf;

MAOTDR 2007, Quadro de Referência Estratégico Nacional - Portugal 2007-2013; MAOTDR, Lisboa, de http://www.qren.pt/item3.php?lang=0\&id_channel=34\&id_page=202;

Mota, Isabel Almeida (ed.) 2007, Estratégia Nacional de Desenvolvimento Sustentável - 2005-2015; de http://www.cnel.gov.pt/document/ENDS-PIENDS_2015.pdf;

SEOTC 2008, Politica de Cidades Polis XXI; de www.dgotdu.pt/PC/documentos/POLISXXI-apresentacao.pdf; 